\title{
Nonlinear adjustment of real exchange rate towards purchasing power parity from G7: An exponential FISTAR modelling
}

\author{
Nadhem Selmi*, Ridha Ettbib and Nejib Hachicha
}

Département de Méthodes Quantitatives, Faculté des Sciences Economiques et de Gestion, BP 1088, Sfax -Tunisie

\begin{tabular}{l}
\hline C H R O N I C L E \\
\hline Article history: \\
Received September 28, 2014 \\
Accepted 28 December 2014 \\
Available online \\
January 122015 \\
\hline Keywords: \\
Fractional integration \\
Smooth Transition Autoregression \\
Purchasing Power Parity
\end{tabular}
\begin{abstract}
A B S T R A C T
The aim of this paper is to study the dynamics of the real exchange rate deviations of G7 countries by capturing nonlinearity and long memory features. In this context, we used fractionally integrated STAR (FISTAR) models proposed by Van Dijk et al. (2002) [Van Dijk, D., Franses, P.H., Paap, R., (2002), A nonlinear long-memory model with an application to US unemployment, Journal of Econometrics, 110, 135-165.] for a case with an exponential transition function. Indeed, this study can take into account procedures characterized by several dynamic regimes and persistence phenomena. Empirically, the elements of both fractional long memory and threshold non-linearity are present for the real exchange rates of the G-7 countries against the US, notably in the EU countries.
\end{abstract}

(C) 2015 Growing Science Ltd. All rights reserved.

\section{Introduction}

The potential presence of stochastic long memory in financial and economic time series has been an important subject of both theoretical and empirical researches. The long-memory phenomenon describes the high-order correlation function of a series. If these series present long memory, there is a persistent temporal dependence among observations widely separated over time horizon. Such series exhibit hyperbolically decaying autocorrelations and low-frequency spectral density. Fractionally integrated processes have a long memory (Mandelbrot, 1977; Granger \& Joyeux, 1980; Hosking, 1981). Alternatively, the short-memory, property describes the low-order correlation function of these series. Short-memory series are characterized by quickly declining autocorrelations and high-frequency spectral density. An autoregressive moving average model cannot exhibit long-run low frequency dependence as they can only describe the short-run high-frequency behavior of a time series. During the recent years, there have been some views towards a significant extension of nonlinear modelling. For instance, in finances and economics, multiple regimes modelling become supplementary and more significant in order to take into account experience characterized for instance by recession or expansion phases, or high or low instability phases. However, a variety of nonlinear models have been proposed 
in the literature to account for this behavior, smooth transition autoregressive (STAR) and fractionally integrated smooth transition autoregressive (FISTAR) models. A nonlinear model of financial time series can also be justified by the existence of asymmetric in variables' dynamics, such as positive shocks and have a more significant and persistent effect than the negative shocks (Christiano et al., 2007). In order to consider these nonlinearities, it is essential to have econometric models to generate diverse dynamics according to the cycle period.

Consequently, this study belongs to a literature exploring, at the same time, these two phenomena of financial and economic time series; namely the long-memory and nonlinear process. We newly proposed what we can call "nonlinear long-memory" models. For instance, some authors provide a joint evidence of mean reversion over long memory and nonlinear exchange rate deviations and stock markets (Choudhri \& Schembri, 2014; de Jesús, et al., 2013). Others propose novel classes of long memory process; for instance, Franses et al. (2002) introduced Switching processes, which show autocorrelation at high lags with an Autocorrelation Function (ACF) that decays at a quicker rate at the beginning in contrast with the autocorrelation function of an ARFIMA model.

The difference in empirical evidence is based on methods under various assumptions concerning data generating process of the exchange rates. In the panel data works, Adiguzel et al. (2014) rely on the panel unit root test that takes into account dependency among series. In a recent study, Lee, and Chou, (2013) utilize nonlinearity approach controlling for structural breaks. Some studies find out the lack of time series behavior (for example McMillan (2009)). There have been several studies that have studied such questions as how the world monetary system will evolve over time and whether the Euro will

exceed the dollar as the leading vehicle currency (see, for example, Chortareas et al., 2011; Katusiime et al., 2015, 2009).

During this work, the fractionally integrated smooth transition autoregressive (FI-STAR) that present another potential application to financial and economic time series was considered (see Boutahar et al. 2009; van Dijk et al. 2002; Smallwood, 2009). Van Dijk et al. (2002) extends the modelling series for specification of these models, such as testing for nonlinearity, parameter estimation and adequacy tests, in the case where the transition function is the logistic function. Smallwood (2008) consider the FISTAR model with an exponential transition function and applies this model to the purchasing power parity puzzle by considering the real exchange rate processes for G7 countries against the United States.

In this paper, we study this group of models as a FI-STAR model. They are defined by some distinct modes in dynamics to obtain the persistence phenomenon. The rest of this paper proposes logistic transition function and introduces a one-step method for the FIESTAR model. This paper is organized as follows. In section 2, we present the FI-STAR model with a transition function and the two-step estimation procedures. In section 3, we analyze the monthly real exchange rate series of G7 countries in order to illustrate the various elements of the modelling FIESTAR process. Finally, section 4 concludes the paper.

\section{The FISTAR model}

\subsection{Introduction of the model}

Let us consider a process $y_{t}$ that satisfies the following long memory scheme:

$$
(1-L)^{d} y_{t}=x_{t}, \quad \mathrm{t}=1, \ldots, \mathrm{T}
$$

where $x_{t}$ is a variance stationary process. The parameter $d$ is possibly no integer in which case, the time series $y_{t}$ is called fractionally integrated (FI) (see Granger \& Joyeux, 1980; Hosking, 1981). 


$$
(1-L)^{d}=\sum_{k=0}^{\infty} \frac{\Gamma(k-d)}{\Gamma(-d) \Gamma(k+1)},
$$

where $\Gamma($.$) is the Gamma function and L$ is the lag operator. If $-\frac{1}{2}<d<\frac{1}{2},\left(x_{t}\right)$ is stationary and invertible. For $0<d<\frac{1}{2},\left(y_{t}\right)$ is a stationary long memory process in the sense that autocorrelations are not absolutely assumable and decays hyperbolically to zero. Finally, if $d>\frac{1}{2},\left(y_{t}\right)$ is nonstationary and the shocks have permanent effects. To capture the nonlinear feature of time series, a wide variety of models can be used (see Franses \& van Dijk, 2000). The smooth transition autoregressive (STAR) model is one of the more popular, it has been empirically developed by Teräsvirta (1994) and is specified by:

$$
y_{t}=\phi_{1,0}+\phi_{1,1} y_{t-1}+\ldots+\phi_{1, p} y_{t-p}+\left(\phi_{2,0}+\phi_{2,1} y_{t-1}+\ldots+\phi_{2, p} y_{t-p}\right) F\left(s_{t} ; \gamma ; c\right)+\eta_{t}
$$

where $\eta_{t}$ is a white noise process, $\gamma$ is the transition parameter $(\gamma>0)$ and $c$ is the threshold parameter; the transition variable $s_{t-m}$ is generally the lagged endogenous variable. In most functions, the transition function $F\left(s_{t}, \gamma, c\right)$ is an exponential function or a logistic function. Purposely, for the Exponential STAR (ESTAR), the transition function takes the subsequent form:

$$
F\left(s_{t-d}, \gamma, c\right)=\left(1-\exp \left\{-\gamma\left(s_{t}-c\right)^{2} / \sigma_{s t}^{2}\right\}^{2}\right) .
$$

Cleary, the transition function is symmetric in that value does not depend on whether the transition variable lies over or below the threshold $c$. Cleary, the parameter $\gamma$ controls the degree of non-linearity. As $\gamma \rightarrow 0$, the transition function depicted in Eq. (4) goes to zero, such as the model in Eq. (3) becomes a simple autoregressive representation. As $\gamma \rightarrow \infty$, the transition function in Eq. (3) converges to unity, and the model in Eq. (3) becomes a different autoregressive model, whose autoregressive coefficients are equal to the sum of the autoregressive coefficients in the two regimes. For the LSTAR family of non-linear models, the transition function is known by:

$$
F\left(s_{t}, \gamma, c\right)=\left(1+\exp \left\{-\gamma\left(s_{t}-c\right) / \sigma_{s t}\right\}\right)^{-1} \text {. }
$$

It is clear that the LSTAR model is preferred when asymmetric behavior is expected in the transition variable. When $\gamma \rightarrow 0$, the LSTAR transition function converges to 0.50 , such as the model in Eq. (3) becomes an autoregressive specification whose coefficients correspond to a geometric average of the autoregressive coefficients, whereas, when $\gamma \rightarrow \infty$ the transition function converges to 1 . In this case, the model of Eq. (3) becomes an autoregressive specification, whose coefficients are the sums of the autoregressive coefficients in the two regimes.

In this paper, we consider the fractionally integrated STAR (FIESTAR) model introduced by van Dijk et al. (2002) (see Smallwood (2005)); it combines the two models was Eq. (1) and Eq. (3) and is given by:

$$
\left\{\begin{array}{l}
(1-L)^{d} y_{t}=x_{t} \\
x_{t}=\phi_{1,0}+\phi_{1,1} x_{t-1}+\ldots+\phi_{1, p} x_{t-p}+\left(\phi_{2,0}+\phi_{2,1} x_{t-1}+\ldots+\phi_{2, p} x_{t-p}\right) F\left(s_{t} ; \gamma ; c\right)+\eta_{t}
\end{array}\right.
$$

where $\eta_{t}$ is a martingale difference series with $E\left[\varepsilon_{t} \mid \Omega_{t-1}\right]=0, E\left[\varepsilon_{t}^{2} \mid \Omega_{t-1}\right]=\sigma^{2}$ and $\Omega_{t}$ is the information set available at time $t$. The FI-STAR model can be also being written as follow: 


$$
(1-L)^{d} y_{t}=\phi_{1}^{\prime} w_{t}\left(1-F\left(s_{t-d} ; \gamma ; c\right)\right)+\phi^{\prime}{ }_{2} w_{t} F\left(s_{t-d} ; \gamma ; c\right)+\eta_{t}
$$

where, $F\left(s_{t}, \gamma, c\right)$ is the transition function governing the movement from one regime to another. The model will be called Logistic FI-STAR (FI-LSTAR) when this purpose is a logistic and Exponential FI-STAR (FI-ESTAR) when it is an exponential. The transition variable is a lagged value of $y_{t}$ i.e. $s_{t}=y_{t-d}$ with $m>0$, where $m$ is the delay parameter. The fractional parameter $d$ and the autoregressive parameters make the FI-STAR model potentially useful for capturing both nonlinear and long-memory features of the time series $y_{t}$. Indeed, as noted by van Dijk et al. (2002), the long run possessions of $y_{t}$ are restricted to be constant and these are determined by the fractional differencing parameter. Therefore, the short-term dynamics are determined by autoregressive parameters.

We present different stages of the specification method for FI-STAR models, as it is proposed by van Dijk et al. (2002):

- Identify a linear ARFI (p) model by choosing the autoregressive order $p$ by means of information criteria (Akaike (1974) or Schwarz (1978)),

- Test the null hypothesis of linearity versus the alternative of a FI-STAR model. If linearity is rejected, choose the appropriate transition variable,

- Determine the parameters in the FI-STAR model,

- Distinguish the model with the test of misspecification (no remaining nonlinearity, parameter constancy, no residual autocorrelation).

\subsection{Test for FISTAR model}

Teräsvirta (1994) developed the technique of testing linearity versus STAR models. He pointed out that this method was complicated which the presence of the unidentified nuisance parameters under the null hypothesis. To overcome this difficulty, he replaced the transition function $F\left(s_{t}, \gamma, c\right)$ by a suitable Taylor series approximation about $\gamma=0$, in the reparametrized equation, the classification problem is no longer present, and linearity can be tested by means of a Lagrange Multiplier (LM) statistic. This technique is extended to FI-LSTAR models by van Dijk et al. (2002) and to FI-ESTAR by Smallwood (2005). The empirical results of Smallwood (2005) show the FI-ESTAR model is more appropriate for modelling real exchange rate dynamic than the FI-LSTAR model. Thus, we dispute only testing linearity versus the FI-ESTAR model specified by:

$$
\left\{\begin{array}{l}
(1-L)^{d} y_{t}=x_{t} \\
x_{t}=\phi_{1}^{\prime}{ }_{1} w_{t}\left(1-F\left(s_{t-d} ; \gamma ; c\right)\right)+\phi^{\prime}{ }_{2} w_{t} F\left(s_{t-d} ; \gamma ; c\right)+\eta_{t} \\
F\left(s_{t-d}, \gamma, c\right)=\left(1-\exp \left\{-\gamma\left(s_{t}-c\right)^{2} / \sigma_{s t}^{2}\right\}^{2}\right)
\end{array}\right.
$$

The difficulty of the presence of unidentified nuisance parameters under the null hypothesis in FISTAR model is approximately the same in STAR model. Thus, the primary order of Taylor development of the exponential transition function around $\gamma=0$ is given by:

$$
G_{1}\left(s_{t}, \gamma, c\right)=\left.G\left(s_{t}, \gamma, c\right)\right|_{\gamma=0}+\left.\gamma \frac{\partial G\left(s_{t}, \gamma, c\right)}{\partial \gamma}\right|_{\gamma=0}+H\left(s_{t}, \gamma, c\right)=\frac{\gamma}{\sigma_{s t}^{2}}\left(s_{t}-c\right)^{2}+H\left(s_{t}, \gamma, c\right)
$$


where $H\left(s_{t}, \gamma, c\right)$ is a remainder expression. Substituting $G_{1}\left(s_{t}, \gamma, c\right)$ for $G\left(s_{t}, \gamma, c\right)$ in the second relationship of combination of Eqs. (7) and reparametrizing terms, the auxiliary regression is specified by:

$$
x_{t}=\theta_{0}{ }^{\prime} w_{t}+\theta_{1}{ }^{\prime} w_{t} s_{t}+\theta_{2}{ }^{\prime} w_{t} s^{2}{ }_{t}+\varepsilon_{t}
$$

With $\quad \theta_{0}=\pi_{1}+\frac{\pi_{2} \gamma c^{2}}{\sigma_{s t}^{2}}, \theta_{1}=-2 \frac{\pi_{2}}{\sigma_{s t}^{2}}, \theta_{2}=\pi_{1}+\frac{\pi_{2} \gamma}{\sigma_{s t}^{2}} \quad$ and $\quad \varepsilon_{t}=\mu_{t}+\beta w_{t} H\left(s_{t}, \gamma, c\right)$. Under $H_{0}: \pi_{2}=0$ or $\gamma=0$ we have $H\left(s_{t}, \gamma, c\right)$ and $\varepsilon_{t}=\mu_{t}$. However the null hypothesis for linearity is specified by $H_{0}: \theta_{1}=\theta_{2}=0$. Therefore the existence of the fractional differencing parameter complicates the construction of the LM type test statistic. Following van Dijk et al. (2002), under the assumption that $\varepsilon_{t} \rightarrow N\left(0, \sigma^{2}\right)$, the conditional log-likelihood for observation $\mathrm{t}$ is specified by:

$$
l_{t}=-\frac{1}{2} \ln 2 \pi-\frac{1}{2} \ln \sigma^{2}-\frac{\varepsilon_{t}^{2}}{2 \sigma^{2}}
$$

The remaining partial derivatives evaluated versus the null hypothesis $H_{0}$ are specified by:

$$
\begin{aligned}
& \frac{\partial l_{t}}{\partial \theta_{i}}=\frac{1}{\sigma^{2}} \hat{\varepsilon}_{t} w_{t} s_{t}^{i}, i=0,1,2 \\
& \frac{\partial l_{t}}{\partial d}=\frac{1}{\sigma^{2}} e_{t} \frac{\partial e_{t}}{\partial d}=-\frac{\hat{\varepsilon}_{t}}{\sigma^{2}} \sum_{j=1}^{t-1} \frac{\hat{\varepsilon}_{t-j}}{j}
\end{aligned}
$$

where $\hat{\varepsilon}_{t}$ are the residuals acquire from the ARFI model under the null hypothesis. Therefore, the LMtype test statistic can be computed in a few steps as follows:

- Approximate an ARFI (p), obtain the set of residuals $\hat{\varepsilon}_{t}$. The total of squared errors, indicated $S S R_{0}$, is then constructed from the residuals $\hat{\varepsilon}_{t}, S S R_{0}=\sum_{t=1}^{T} \hat{\varepsilon}_{t}^{2}$,

- Regress $\hat{\varepsilon}_{t}$ on $w_{t},-\sum_{j=1}^{t-1} \frac{\hat{\varepsilon}_{t-j}}{j}$ and $w_{t} s_{t}^{i}$ calculate the sum of squared residuals $S S R_{1}$ versus the alternative hypothesis,

- The $\chi^{2}$ version of the LM test statistic is given by:

$$
L M_{\chi^{2}}=\frac{T\left(S S R_{0}-S S R_{1}\right)}{S S R_{0}}
$$

and is distributed as $\chi^{2}(2(p+1))$ versus $H_{0}$ (T denotes the sample dimension). The Fisher version ${ }^{1}$ of the LM test statistic is specified by:

$$
L M_{F}=\frac{\left(S S R_{0}-S S R_{1}\right) / 2(p+1)}{S S R_{1} /(T-3(p+1))},
$$

and is distributed as an $F(2(p+1),(\mathrm{T}-3(p+1)))$ statistic versus $H_{0}$.

\section{Data and empirical estimates}

\subsection{Data}

${ }^{11}$ The Fisher version is favoured than $\chi^{2}$ when the sample size is little and that the selected delay is significant. 
In this section, we consider tests and estimation results for the monthly real exchange rates dynamics of the G7 countries against the United States. All data employed in this study were obtained from the International Financial Statistics. The nominal exchange rate has been defined as the number of units of the domestic currency that can purchase a unit of a given foreign currency. Both the domestic and foreign consumer price indexes are used as proxies for measuring price levels of each country's output. For French, Germany and Italy, the monthly data extend from January 1960 to December 1998. For Japan, Canada and the U.K, the data extend from January 1960 to September 2008. The PPP hypothesis can be tested by estimating the regression:

$$
s_{t}=\beta_{0}+\beta_{1} p_{t}+\beta_{2} p_{t}^{*}+r_{t}
$$

where $\beta_{0}$ is some constant, $s_{t}$ is the logarithm of the foreign price of domestic currency, $p_{t}$ and $p_{t}^{*}$ are the logarithms of the domestic and foreign consumer price levels, respectively, at time $t$ and $r_{t}$ is a disturbance term capturing the real exchange rate deviations from PPP at time $t$. Both $p_{t}$ and $p_{t}^{*}$ are used as proxies for measuring price levels for each country's. The parameters, $\beta_{0}, \beta_{1}$ and $\beta_{2}$ can be estimated using Engle and Granger method and the results residuals which are taken to be the estimated real exchange rate.

As reported in Table 1, the Engle and Granger (1987) procedure provides evidence of cointegration among nominal exchange rates and domestic and foreign consumer price index for all countries ${ }^{2}$. The nonlinearity tests and subsequent analysis are applied to the series of deviations from PPP as estimated by the Engle and Granger method. The length of the linear ARFI, $p$, for the real exchange rate series is chosen on the basis of the Ljung-Box portmanteau test to ensure the absence of residual autocorrelation up to order 12. Both the Ljung-Box portmanteau test indicate that an ARFI model with $p=1$ is adequate for Canada, Germany, Italy and United Kingdom with $p=3$ is adequate for France and Japan with $p=6$ is adequate.

\section{Table 1}

Engle and Granger cointegration results for the PPP

\begin{tabular}{ccccc}
\hline Countries & $s_{t}$ & constant & $p_{t}$ & $p_{t}^{*}$ \\
\hline Canada & 1 & 0.2336 & 0.689 & -0.682 \\
French & 1 & 2.4145 & 0.705 & -0.860 \\
Germany & 1 & 4.3536 & -0.768 & -0.0473 \\
\hline Italy & 1 & 6.3106 & -0.486 & -0.239 \\
UK & 1 & -0.127 & -0.649 & 0.781 \\
\hline Japan & 1 & 8.31099 & 0.244 & -1.034 \\
U.K & 1 & -0.1272 & -0.649 & 0.781 \\
\hline
\end{tabular}

\subsection{Linearity test}

The linearity tests are displayed in Table 2. Using a 95\% criterion, we have found that 5 out of 6 countries, France, Germany, Italy, Canada and the UK, decisively reject the null hypothesis of linearity in favor of the FIESTAR specification. We conclude that linear cointegration tests may have been weakened by the nonlinear nature of the relationship between elements of the real exchange rate. In contrast, we fail to reject the linearity for Japan regardless for whether $\mathrm{m}$ is estimated under the null or alternative hypothesis. Further, the test results from the estimated real exchange rate using Engle and

2 All variables have been tested for the presence of a unit root using the Agmented Dickey-Fuller and KwiatkowaskiPhillips-Schmidt-Shin tests. Consistent with the literature, the null hypothesis of a single unit root cannot be rejected. To conserve space these results are not reported here but available upon request. 
Granger method indicates that the non-linearity is present for France, Germany, Italy, Canada and the UK, but again, not for Japan.

The result of nonlinear adjustment in the real exchange rate deviation from PPP is probably due to central banks' interventions aimed at avoiding excessive appreciation or depreciation of a currency. Intuitively, monetary authorities may intervene in the foreign exchange market as a reaction to large depreciations or appreciations of a currency, which lead to different behavior for moderate and large changes of the exchange rate.

Table 2

Linearity test (p-value)

\begin{tabular}{lccc}
\hline Countries & Dealy parameter & $L M \chi^{2}$ & $L M F$ \\
\hline Canada & $\mathrm{m}=1$ & $0.00178^{*}$ & $0.00172^{*}$ \\
French & $\mathrm{m}=2$ & $0.0152^{*}$ & $0.0153^{*}$ \\
Germany & $\mathrm{m}=1$ & $0.0159^{*}$ & $0.01571^{*}$ \\
Italy & $\mathrm{m}=3$ & $0.0017^{*}$ & $0.00161^{*}$ \\
United Kingdom & $\mathrm{m}=5$ & $0.0124^{*}$ & $0.0124^{*}$ \\
\hline Note: If linearity is rejected for more than one value of $\mathrm{m}$, the $\mathrm{m}$ is chosen so that it minimizes the $\mathrm{m}$ is chosen so that is minimizes the P-value of the \\
linearity test. Asterisks indicate the minimum P-value over the interval $1 \leq m \leq 6$.
\end{tabular}

In this section, we present the results of testing of nonlinearity (Table 2) via artificial regression (2.5) including the delay order chosen by the sequence of tests as providing the strongest evidence. The value of the delay parameter varies between 1 and 5 across countries, while Canada and Germany have $m=1$ , France have $m=2$, Italy have $m=3$ and United Kingdom have $m=5$. For example, the choice of the optimal lag length $m=5$, for the United Kingdom, suggests that the five lag of the real exchange rate series contributes most prominently to the nonlinear adjustment of the current value.

\subsection{An Empirical Results}

Estimation results for the ARFI, ESTAR, and FIESTAR models are shown in Table 3. Following the modelling the Real Exchange Rate Adjustments in G7, we start by specifying a linear ARFI model. We allow for a maximum autoregressive order of $p=12$.

Table 3 presents the estimation results based on the preferred for each real exchange rate. For Japan, we present the results concerning the estimated linear ARFIMA model. The estimate linear ARFIMA models provide little support for the theory of PPP. For Japan, the estimate of the fractional differencing of $d=0.077$ suggests that the real exchange rate deviation for Japan is stationary and mean reverting. For Canada and the U.K, we are unable to reject the hypothesis that $d=0$ and thus present estimates from the ESTAR model.

In order to specify the nonlinear adjustment in real exchange rate deviations to PPP in presence of the transaction costs, we will estimate a ESTAR model for real exchange rates deviations, for Canada and the UK, that is,

$$
\Delta y_{t}=\phi_{0}^{1}+\lambda^{\prime} y_{t-1}+\sum_{i=1}^{p-1} \phi_{i}^{1} y_{t-i}+\left(\phi_{0}^{2}+\lambda^{\prime \prime} y_{t-1}+\sum_{i=1}^{p-1} \phi_{i}^{2} y_{t-i}\right) \times F\left(y_{t-m}, \gamma, c\right)+\mu_{t}
$$

The estimate parameters are presented in the Table 4. The critical parameters in ESTAR models are $\lambda^{\prime}+\lambda^{\prime \prime}<0, \gamma$ and $c$. The estimates of $\gamma$ is expected to be positive sign and significantly different from zero in Canada and the United Kingdom. The parameter $c$ indicates the halfway point between appreciation and depreciation phases of the real exchange rate. In all countries, the estimates of $\mathrm{c}$ is 
significant at level of 5 and $10 \%$. However the global stability condition that $\lambda^{\prime}+\lambda^{\prime \prime}<0$ is satisfied in all countries.

\section{Table 3}

Estimation results based on the preferred model for the real exchange rate

\begin{tabular}{|c|c|c|c|c|c|c|}
\hline Coefficients/countries & Japan & Canada & UK & French & Germany & Italy \\
\hline$\mu_{1}$ & $\begin{array}{l}0.003 \\
(0.02)\end{array}$ & $\begin{array}{c}0.03 \\
(0.02)\end{array}$ & $\begin{array}{c}0.05 \\
(0.03)\end{array}$ & $\begin{array}{c}0.69 \\
(0.40)\end{array}$ & $\begin{array}{c}0.06 \\
(0.06)\end{array}$ & $\begin{array}{l}0.0005 \\
(0.00)\end{array}$ \\
\hline$\varphi_{2}(1)$ & $\begin{array}{c}0.86 \\
(0.04)\end{array}$ & $\begin{array}{c}0.74 \\
(0.52)\end{array}$ & $\begin{array}{c}0.27 \\
(0.39)\end{array}$ & $\begin{array}{c}0.67 \\
(0.34)\end{array}$ & $\begin{array}{c}2.17 \\
(0.71)\end{array}$ & $\begin{array}{c}0.88 \\
(0.21)\end{array}$ \\
\hline$\varphi_{2}(2)$ & $\begin{array}{c}0.05 \\
(0.05)\end{array}$ & - & $\begin{array}{c}0.53 \\
(0.35)\end{array}$ & $\begin{array}{c}2.80 \\
(1.61)\end{array}$ & $\begin{array}{l}-0.002 \\
(0.59)\end{array}$ & $\begin{array}{l}-0.33 \\
(0.28)\end{array}$ \\
\hline$\varphi_{2}(3)$ & $\begin{array}{c}0.07 \\
(0.05)\end{array}$ & - & $\begin{array}{c}0.50 \\
(0.31)\end{array}$ & $\begin{array}{c}0.27 \\
(0.56)\end{array}$ & $\begin{array}{c}0.25 \\
(0.44)\end{array}$ & $\begin{array}{c}0.99 \\
(0.47)\end{array}$ \\
\hline$\varphi_{2}(4)$ & $\begin{array}{l}-0.09 \\
(0.05)\end{array}$ & - & - & $\begin{array}{c}0.25 \\
(0.45)\end{array}$ & - & - \\
\hline$\varphi_{2}(5)$ & $\begin{array}{c}0.06 \\
(0.05)\end{array}$ & - & - & $\begin{array}{l}-0.62 \\
(0.59)\end{array}$ & - & - \\
\hline$\varphi_{2}(6)$ & $\begin{array}{l}-0.08 \\
(0.04)\end{array}$ & - & - & $\begin{array}{l}0.111 \\
(0.50)\end{array}$ & - & - \\
\hline$\varphi_{2}(7)$ & $\begin{array}{c}0.08 \\
(0.04)\end{array}$ & - & - & & - & - \\
\hline$\mu_{2}$ & - & $\begin{array}{l}-0.03 \\
(0.02)\end{array}$ & $\begin{array}{l}-0.05 \\
(0.03)\end{array}$ & $\begin{array}{l}-0.69 \\
(0.40)\end{array}$ & $\begin{array}{l}-0.06 \\
(0.06)\end{array}$ & $\begin{array}{c}0.007 \\
(0.005)\end{array}$ \\
\hline$\varphi_{2}(1)$ & - & $\begin{array}{l}-0.76 \\
(0.52)\end{array}$ & $\begin{array}{l}-0.78 \\
(0.39)\end{array}$ & $\begin{array}{c}0.40 \\
(0.36)\end{array}$ & $\begin{array}{l}-1.49 \\
(0.60)\end{array}$ & $\begin{array}{c}0.06 \\
(0.21)\end{array}$ \\
\hline$\varphi_{2}(2)$ & - & - & $\begin{array}{l}-0.64 \\
(0.36)\end{array}$ & $\begin{array}{l}-2.77 \\
(1.61)\end{array}$ & $\begin{array}{c}0.15 \\
(0.59)\end{array}$ & $\begin{array}{c}0.45 \\
(0.31)\end{array}$ \\
\hline$\varphi_{2}(3)$ & - & - & $\begin{array}{l}-0.52 \\
(0.31)\end{array}$ & $\begin{array}{l}-0.28 \\
(0.58)\end{array}$ & $\begin{array}{l}-0.19 \\
(0.42)\end{array}$ & $\begin{array}{l}-1.08 \\
(0.48)\end{array}$ \\
\hline$\varphi_{2}(4)$ & - & - & - & $\begin{array}{l}-0.26 \\
(0.47)\end{array}$ & - & - \\
\hline$\varphi_{2}(5)$ & - & - & - & $\begin{array}{c}0.64 \\
(0.61)\end{array}$ & - & - \\
\hline$\varphi_{2}(6)$ & - & - & - & $\begin{array}{l}-0.20 \\
(0.51)\end{array}$ & - & - \\
\hline$\gamma / \sigma^{2}$ & - & $\begin{array}{l}28.1809 \\
(18.422)\end{array}$ & $2.8675(1.2729)$ & $\begin{array}{c}23.2947 \\
(12.3366)\end{array}$ & $\begin{array}{c}58.351 \\
(364894)\end{array}$ & $\begin{array}{c}13.6985 \\
(8.4396)\end{array}$ \\
\hline $\mathrm{c}$ & - & $\begin{array}{r}-0.0422 \\
(0.005)\end{array}$ & $-0.2927(0.0106)$ & $-0.2257(0.0091)$ & $\begin{array}{l}-0.1212 \\
(0.0052)\end{array}$ & $\begin{array}{r}-0.0146 \\
(0.009)\end{array}$ \\
\hline d & $0.0775(0.038)$ & - & - & $-0.0814(0.0446)$ & $\begin{array}{l}0.3092 \\
(0.189)\end{array}$ & $\begin{array}{c}0.962 \\
(0.059)\end{array}$ \\
\hline$\sigma^{2}$ & - & 0.007 & 0.014150 & 0.02157265 & 0.02035 & 0.0172 \\
\hline$\gamma$ & - & 0.1993 & 0.04057569 & 0.50252841 & 1.1878 & 0.2368 \\
\hline $\mathrm{Q}(1)$ & 0.912 & 0.9324 & 0.9723 & 0.9105 & 0.6810 & 0.7928 \\
\hline $\mathrm{Q}(4)$ & 0.999 & 0.5415 & 0.8167 & 0.9996 & 0.8593 & 0.9429 \\
\hline $\mathrm{Q}(12)$ & 0.339 & 0.6353 & 0.1466 & 0.8535 & 0.6023 & 0.2217 \\
\hline $\mathrm{Q}^{1}(1)$ & $8.405 .10^{-4}$ & 0.000 & 0.0002 & 0.1446 & 0.00027 & 0.0018 \\
\hline $\mathrm{Q}^{2}(4)$ & $1.2326 .10^{-3}$ & 0.000 & 0.0006 & 0.2109 & 0.00062 & 0.00028 \\
\hline $\mathrm{Q}^{2}(12)$ & $1.123 .10^{-4}$ & 0.000 & 0.0160 & 0.1423 & 0.0015 & 0.00019 \\
\hline
\end{tabular}

Notes: The numbers in parentheses are the t-statistics for the corresponding estimates. P-val Q and P-val Q ${ }^{2}$ are the p-values for the Ljung-Box Q-statistics for the hypothesis of serial correlation in the residuals and squared residuals, respectively. The numbers appearing in brackets beneath the parameter estimates are numerical standard errors.

Residual diagnostics indicate that the model provides a clearly acceptable representation for the adjustment process toward PPP. Since we use monthly data, residuals are tested for $12^{\text {th }}$ order autocorrelation and ARCH effects. The P-values reject serial correlation and the presence of ARCH non-linearity in the residuals for all countries. The estimation of the Exponential Smooth Transition confirms the findings of previous studies and shows clearly the existence of nonlinear adjustment of linear exchange rate towards PPP and the speed of adjustment depends both on the size and on the sign 
of the deviation from PPP. In addition, many economic variables in particular real exchange rate, may present symmetric speed of mean reversion. This implies the existence of two regimes, i.e. in the inner regime the variable behaves as a unit roots process, whereas in the outer regime the variable reverts to the equilibrium value. Controlling this source of nonlinearity is interesting when dealing with the exchange rate, since policy makers may not decide to react when the exchange rate is within the range of some values, given that the costs of any policy decision may overwhelm the benefits. However, when the exchange rate exceeds a given threshold, the monetary authority might intervene in the markets in order to return the exchange rate to a more sensible value. Consider the FIESTAR models, the critical parameters are $d, \gamma$ and $c$. In particular, the estimate of $d$ is equal to $-0.0814,0.3092$ and 0.0962 for France, Germany and Italy, respectively. For these countries, the estimate of the fractional integration parameter was significantly different from both 0 and 1 and belongs to the interval $\left.]-\frac{1}{2}, \frac{1}{2}\right]$ suggesting that the process is stationary and invertible. The speed of mean reversion $\gamma$ is positive and significantly different from 0 . In particular, the estimate of $\gamma$ is equal to $0.502,1.187$ and 0.0 .236 for France, Germany and Italy, respectively. The PPP equilibrium is reached, but the speed of adjustment is very slow. This indicates that the nominal exchange rate and consumer prices index can oscillate substantially above and below the equilibrium for an exceptional long time. The parameter $c$ indicates the halfway point between the different phases of the exchange rate. The estimate of $c$ is negative and significantly different from zero in these countries. The nonlinearity of the transition is unambiguous, although it should only be taken as indicative. The coefficient $c$ could be viewed as the equilibrium value of the real exchange rate. The negative values of $\left(y_{t-m}-c\right)$ correspond to the period of economic turmoil. These figures confirm the nonlinearity of the real exchange adjustment and the appropriateness of the exponential transition function. This implies that the real exchange rates of these countries have symmetrical responds towards appreciation and depreciation.

These results confirm the recent theoretical analyses for modelling the real exchange rate dynamics in the presence of transaction costs and other barriers to trade. Dumas (1992), while analyzing the dynamic process of real exchange rates in spatially separated markets under proportional transaction costs, proved a nonlinear adjustment process toward PPP. Deviations from PPP are shown to follow a nonlinear process that is mean-reverting, with the speed of adjustment toward equilibrium varying directly with the extent of the deviation from PPP. Within the transaction band, when no trade takes place, the process is divergent so that the exchange rate spends most of the time away from parity. This implies that deviations from PPP last for a very long time, although they certainly do not follow a random walk.

\section{Conclusion}

The aim of this paper was to study the real exchange rates deviations of the G7 countries. We considered the FI-ESTAR model, as proposed by van Dijk et al. (2002), which could describe long memory and nonlinearity, simultaneously. The analysis of this paper shows that there was an evidence of both ESTAR non linearity and fractional long memory in the dynamics associated with PPP for French, Germany and Italy. There was a little evidence of ESTAR non-linearity for the real exchange rates deviation of Japan. The real exchange rate deviation of the Canada and UK could be characterized by nonlinear feature.

\section{References}

Adiguzel, U., Sahbaz, A., Ozcan, C. C., \& Nazlioglu, S. (2014). The behavior of Turkish exchange rates: A panel data perspective. Economic Modelling, 42, 177-185.

Akaike, H. (1974). A new look at the statistical model identification. IEEE Transactions on Automatic Control, 19(6), 716-723. 
Boutahar, M., Mootamri, I., \& Feissolle, P. A. (2009). A fractionally integrated exponential STAR model applied to the US real effective exchange rate. Journal of Economic Modelling, 26, 335-341.

Chortareas, G., Jiang, Y., \& Nankervis, J. C. (2011). The random-walk behavior of the euro exchange rate. Finance Research Letters, 8(3), 158-162.

Choudhri, E. U., \& Schembri, L. L. (2014). Productivity, commodity prices and the real exchange rate: The long-run behavior of the Canada-US exchange rate. International Review of Economics \& Finance, 29, 537-551.

Clarida, R. H., \& Taylor, M. P. (2003). Nonlinear permanent-temporary decomposition, with applications in macroeconomics and finance. The Economic Journal, 113, 125-139.

de Jesús, R., Ortiz, E., \& Cabello, A. (2013). Long run peso/dollar exchange rates and extreme value behavior: Value at Risk modeling. The North American Journal of Economics and Finance, 24, 139152.

Dickey, D. A., \& Fuller, W. A. (1979). Distribution of the estimators for autoregressive time series with a unit root. Journal of the American Statistical Association, 74, 27-431.

Elliot, G., Stock, J.H., \& Rothenberg, T., (1996). Efficient tests of an autoregressive unit root. Econometrica, 64, 813-836.

Engle, R., \& Granger, C. (1987). Cointegration and error correction: representation, estimation and testing. Econometrica, 55, 251-276.

Eun, C. S., Kim, S. H., \& Lee, K. (2014). Currency competition between the dollar and euro: Evidence from exchange rate behaviors. Finance Research Letters.

Franses, P. H., \& Paap, R. (2002). Censored latent effects autoregression, with an application to US unemployment. Journal of Applied Econometrics, 17, 347-366.

Franses, P. H., \& van Dijk, D., (2000). Nonlinear Time Series Models in Empirical Finance. Cambridge University Press, Cambridge.

Granger, C. W. J., \& Joyeux, R. (1980). An introduction to long-range time series models and fractional differencing. Journal of Time Series Analysis, 1, 15-29.

Hosking, J. R. M., (1981). Fractional differencing. Biometrika, 68, 165-176.

Katusiime, L., Shamsuddin, A., \& Agbola, F. W. (2015). Macroeconomic and market microstructure modelling of Ugandan exchange rate. Economic Modelling, 45, 175-186.

Kwiatkowski, D., Phillips, P.C.B., Schmidt, P., \& Shin, Y. (1992). Testing the null hypothesis of stationarity against the alternative of a unit root. Journal of Econometrics, 54,159-178.

Mandelbrot, B.B. (1977). Fractals: Form, Chance, and Dimension. Free Press, New York.

McMillan, D. G. (2009). The confusing time-series behaviour of real exchange rates: Are asymmetries important?. Journal of International Financial Markets, Institutions and Money, 19(4), 692-711.

Phillips, P.C.B., \& Perron, P. (1988). Testing for a unit root in time series regression. Biometrika, 75, 335-346.

Sarantis, N. (1999). Modelling non-linearities in real effective exchange rates. Journal of International Money and Finance, 18, 27-45.

Sarno, L., \& Taylor, M. (2001). Real exchange rate dynamics in transition economies: a nonlinear analysis. Studies in Nonlinear Dynamics and Econometrics, 5, 153-177.

Schwarz, G. (1978). Estimating the dimension of a model. Annals of Statistics, 6, 461-464.

Smallwood, A. D. (2005). Joint tests for long memory and non-linearity: the case of purchasing power parity. Studies in Nonlinear Dynamics and Econometrics, 9, 1-28.

Smallwood, A. D. (2008). Measuring the persistence of deviations from purchasing power parity with a fractionally integrated STAR model. Journal of International Money and Finance, 27, 1161-1176.

Taylor, M.P., Peel, D.A., \& Sarno, L. (2001). Nonlinear mean-reversion in real exchange rates: toward a solution to the purchasing power parity puzzles. International Economic Review, 4, 1015-1041.

Teräsvirta, T. (1994). Specification, estimation, and evaluation of smooth transition autoregressive models. Journal of the American Statistical Association, 89, 208-218.

van Dijk, D., Franses, P. H., \& Paap, R. (2002). A nonlinear long-memory model with an application to US unemployment. Journal of Econometrics, 110, 135-165. 